Home / Books / Developments in Corporate Governance and Responsibility / Governance and Sustainability, Volume 15 / Communication of the Commitment to Sustainability and the UN SDGs in the Iberian Foundations

\title{
Communication of the Commitment to Sustainability and the UN SDGs in the Iberian Foundations
}

Ana Fialho, Elisabete Gomes Santana Félix, Fátima Jorge, Maria Del Mar Soto Moya

Governance and Sustainability

ISBN: 978-1-80043-152-2, elSBN: 978-1-80043-151-5

ISSN: 2043-0523

Publication date: 21 October 2020

Reprints \& Permissions

\begin{abstract}
The study will present contributions at several levels: literature and practice. It makes contributions to the literature on relationships between sustainability practices and sustainability report and the regulation and institutionalization of sustainability practices and reporting for SDGs. Also, our study contributes to a better understanding of the role of Iberian Foundations as partners in achieving the Global Goals and their contribution to the effective, responsible and transparent development of institutions for United Nations 2030 Agenda for Sustainable Development.
\end{abstract}

\section{Keywords}

\author{
Sustainability UN SDGs Iberian foundations Annual reports Communication \\ Accountability
}

\section{Citation}

Fialho, A., Santana Félix, E.G., Jorge, F. and Del Mar Soto Moya, M. (2020), "Communication of the Commitment to Sustainability and the UN SDGs in the Iberian Foundations", Crowther, D. and Seifi, S. (Ed.) Governance and Sustainability (Developments in Corporate Governance and Responsibility, Vol. 15), Emerald Publishing Limited, pp. 91-111. https://doi.org/10.1108/S2043052320200000015006

崩 Download as .RIS

Publisher: Emerald Publishing Limited

Copyright @ 2020 Emerald Publishing Limited

To read the full version of this content please select one of the options below

You may be able to access this content by logging in via Shibboleth, Open Athens or with your Emerald Account.

If you think you should have access to this content, click the button to contact our support team.
Login

(옹 